\title{
Research on the Factors Affecting Customer Engagement in Social Commerce from the Perspective of Two-Factor Theory
}

\section{-- Platform Comparison Between E-Commerce and Social Media}

\author{
Saisai Qiao ${ }^{1}$, Jie Wei $^{2, *}$ \\ ${ }^{1}$ Department of Management, Shanghai University, Shanghai, 200000, China \\ ${ }^{2}$ Department of Management, Shanghai University, Shanghai, 200000, China \\ * Corresponding author: Jie Wei (Email: lovelyyinhuli@hotmail.com)
}

\begin{abstract}
As a new type of business model, social commerce has attracted more attention. we propose a model to explore the factors influencing customer engagement by using the two-factor theory, as well as the effect of customer engagement on subsequent participation behavior. The results show that both social support and self-congruence have a positive impact on customer engagement, while perceived engagement risk and perceived commerce risk have a significant negative impact on customer engagement, moreover, customer engagement is positively related to social sharing and purchase intention. In addition, this paper verifies the comparative effect of social commerce platforms. The results show that there are significant differences in social support and self-congruence between e-commerce and social media platforms.
\end{abstract}

Keywords: Customer engagement, Self-congruence, Social support, Perceived risk, Platform comparison.

\section{Introduction}

Social media platforms can gather a large number of highly active and sticky customers in a short period of time, showing a strong development potential. Inspired by social networking sites, many enterprises integrate social media functions with e-commerce functions, and gradually form a new business model -- social commerce [1]. Social commerce is defined as the use of Web 2.0 applications and social media to promote the interaction of individuals on the Internet to support the process of customer purchasing products or services [2]. Social commerce can increase sales by providing customers with a more interactive shopping experience [3]. Customers on the Internet can develop good social relationships with others, so that they can help others and receive advice during their purchase process [4]. With the changing of such shopping mode, customers are gradually keen on obtaining information and shopping on social commerce websites.

The business model based on customer engagement makes social commerce a rapidly growing way of online buying and selling. Customer is usually powerful in explaining and predicting the results of customer behavior [5]. High customer retention and engagement can promote business growth and increase profits [6]. In the future, about $1 / 3$ of the world's population will consume through social commerce platforms [7]. This huge customer base provides opportunities for the development of Internet platforms.

However, there are still some problems in the field of social commerce. First, although customer engagement can be used to measure platform competitiveness, fierce market competition and low switching costs of customers make it more difficult for a platform to attract customers' attention and participation [8]. In this respect, how to promote customer engagement is a crucial issue for both scholars and platforms. Second, there have been numerous literature studies on positive factors affecting customer engagement, less research on the factors that have negative effects. Based on the current situation, this study attempts to solve the above challenges. The first question is which factors have a positive or negative impact on customer. Secondly, the different platforms on which customer engage on social commerce are also worth paying attention to. Most of the existing studies focus on a single social platform, and there is still no systematic study on the difference between the two types of social commerce platforms. Therefore, the third research question is: do e-commerce and social media platforms have different impacts on customer engagement?

\section{Literature Review and Hypotheses Development}

\subsection{Sor Theory}

SOR (Stimuluation-Organism-Response) theory is the basic theory in the field of customer behaviours. On the field of social commerce, stimuluation (S) means the environmental factors that stimulate the emotions of individuals [9]. Organism $(\mathrm{O})$ refers to the inner mechanical state of individuals. Response (R) means the active intendecy and actual perfermance which show after ones are stimulated. This paper integrates SOR theory to measure social business customer behavior.

\subsection{Customer Engagement}

According to the service-oriented logic, customer engagement is a psychological state generated by the interaction with the focal agent or object in the service relationship, which is jointly determined by the cognitive, emotional and behavioral dimensions of customers. Thus, this 
paper uess second-order constructs (absorption, dedication and vigor) to measure customer engagement [10]. Absorption refers to the embodiment of customers' cognition and the state of their immersion and dedication when using social commerce websites. Dedication are the emotional level of interest, enthusiasm and inspiration shown by customers. Vigor is a behavioral measure of how much effort and time customers are willing to put into using a website.

\subsection{Two-factor Theory}

As for the factors that influence customer engagement, there is little discussion on the negative factors that affect customer engagement. Therefore, we will expand the twofactor theory to this field in the following to explore the factors that affect customer psychological engagement from both positive and negative perspectives to help solve this problem.

In the field of information systems, the functional value of a product or organization can be classified as hygiene factors, which are the factors that inhibit customers from using products or services [11]. The higher the strangeness and uncertainty of customers to the environment, the more likely it is to affect the psychological state of customers, thus inhibiting the tendency of customers to use products or services. The customer's sense of uncertainty about the potential negative consequences of using a product or service, namely perceived risk [12]. Therefore, we attempt to explore the impact of perceived risk on customer engagement by using perceived risk as a hygiene factor. Engagement risk refers to privacy risk and social risk, and is a customer's assessment of the potential negative consequences of an action on social commerce.

For social commerce, motivation factors are the key to determining whether customers participate in online interaction, as well as whether customers purchase from specific online stores [13].

From the individual point of view, the motivation of craving for recognition can be an important factor to stimulate the psychological changes of customers. The fundamental reason for individuals to match their self-identity with the image represented by the organization is to obtain the approval of others, which is the dominant role of selfcongruence. Self-consistence is defined as "the degree of cognitive matching between consumers' self-concept and product/organizational image" [14]. Research shows that selfcongruence can improve customers' response to brand emotion, attitude and behavior [15]. Therefore, we try to explore whether self-congruence can motivate customers to engage on social commerce.

From the perspective of social interaction, people tend to communicate and discuss product or service information with others in the context of social commerce, seeking opinions and feedbacks from social contacts, that is, seeking social support. Social support refers to an individual's feeling of being cared for, responded to, and helped by people in a social group [2]. Social support is an important indicator to measure customer engagement and positive behavior. Therefore, this paper tries to explore whether social support can motivate customer engagement on social commerce.

\subsection{Customer Behavioral Intention}

Customer behavioral intention can be divided into social sharing intention and purchase intention. Social sharing intention is one of the main factors to measure social commerce activities [16], and it can represent consumers' tendency of social interaction behavior. According to the theory of consumer behavior, purchase intention refers to the tendency of customers to make a purchase decision for the products or services, which is a behavioral tendency. The reason for the occurrence of customers' behavioral intention can be explained as the change of customers' psychological state when they participate in the interaction of social commerce sites. When a customer browsing the site, customers participate in website can contact the enterprises or organizations to establish a powerful psychological, this increases the possibility of respond to the enterprise, the organization and its product [17]. The response can bring profits and create value for enterprises. Therefore, customer behavior intention is one of the following topic.

\section{Hypothesis and Research Model}

\subsection{Self-congruence}

Research believes that a high level of self-congruence indicates there is a good match between customers and enterprises, which will affect customers' cognition and emotion, thus encouraging them to participate in social commerce websites [18]. For example, many customers will buy high-value brands as a symbol of their identity [19] or will participate in website interaction. When comparing selfconcept with social commerce websites, if customers realize they have high self-congruence, it means there is a good match between customers and social commerce websites, which may increase the participation of customers of social commerce. Therefore, the following hypotheses are proposed:

$\mathrm{H} 1$ : For social commerce, self-congruence has a positive impact on customer engagement.

\subsection{Social Support}

ALADWANI [20] found that the quality of social support has a significant impact on customer engagement in social business [21]. People need social communication to meet their needs for social belonging and support [2]. When customers benefit from social support, they are likely to develop a sense of mutual responsibility that leads them to provide support to other community members [22], and when they establish personal connections with others, they can get the feeling of contact with others through the site, which increases the social presence of customers and will eventually lead to the increase of the use behavior of the site [21]. Therefore, it can be assumed that:

$\mathrm{H} 2$ : For social commerce, self-congruence has a positive impact on customer engagement.

\subsection{Perceived Risk}

Decision field theory holds that risk is an important consideration in decision making, because in the process of online shopping, the biggest obstacle is risk [1]. Typical social commerce behaviors (purchasing and posting comments) are likely to bring some risks to customers, which may hinder customers' participation in social commerce activities [23] and seriously affect the decision-making results. Even if customers do not know whether the perceived risk will occur, the higher the risk they perceive psychologically, the more it will become one of the major obstacles to making decisions[24]. In addition, risk is also an important factor affecting social interaction [25]. Therefore, this paper proposes the following hypotheses: 
H3: For social commerce, perceived engagement risk has a negative impact on customer engagement.

H4: For social commerce, perceived commerce risk has a negative impact on customer engagement.

\subsection{Social Sharing Intention}

When customers are willing to invest time and energy into the site, have a strong interest in the website, and feel enthusiasm and significance from the platform, they will have a tendency to generate certain information in the process of using the website, such as browsing and comments. Active customers can provide some valuable information in the Internet, such as the advantages and disadvantages of goods [26]. Similarly, customer engagement can improve the possibility of evaluating products and services, which will also have a positive impact on word-of-mouth [10]. Therefore, we propose:

H5: For social commerce, customer engagement has a positive impact on social sharing intention.

\subsection{Purchase Intention}

CHEUNG, LEE [10] believe that customer engagement should have a positive impact on specific engagement behaviors. Moreover, customers who participate in the website are more satisfied with the site than other customers [27], that is to say, customers are more willing to put their personal energy (from the emotional and cognitive aspects) into an online social platform, so he/she is more inclined to participate in the activities on the online social platform in action. Therefore, this paper proposes:

H6: For social commerce, customer engagement has a positive impact on purchase intention.

\subsection{Differences between E-commerce and Social Media Platforms}

The customer's judgment on this self-congruence will be influenced by others. The main purpose of customers using ecommerce is to shop efficiently and to interact with others less, but the goal of using social media is to face the society more and interact with others. Because customers have more social interactions in social media and are more vulnerable, the hypothesis is put forward:

H7a: Compared with e-commerce websites, the selfcongruence of social media websites has more significant influence on customer engagement.

After adding social elements to the e-commerce, customers who have not communicated can establish their relationship through social interaction and social support exchange, which can greatly affect their decision-making behavior [2, 4]. At present, all social networking sites have not realized the true identity authentication of customers. This situation makes customers communicate more carefully when they communicate on social platforms, in order to protect their own information, thus affecting their engagement behavior. That is to say, engagement status of customers in the second case may be weaker than that in the first case. Therefore, this paper puts forward the hypothesis:

H7b: Compared with social media websites, the influence of social support on customer engagement on e-commerce websites has more significant influence.

When customers use social media websites, a lot of websites do not use real-name system. Each customer must register an account with ID number before using the ecommerce, which ensures the security of customers participating in social interaction. Moreover, people on EC can interact anonymously, which greatly reduces the possibility of revealing the true identity of customers and the engagement of customers. Surveys show that around $52 \%$ of Google customers and $70 \%$ of Facebook customers are somewhat or very concerned about privacy when using services [28]. Compared with social media, online shopping websites/stores have stronger security and better privacy system [29]. Therefore, we assume that:

H7c: There are significantly differences between ecommerce and social media platforms in the impact of perceived engagement risk on customer engagement.

H7d: There are significantly differences between ecommerce and social media platforms in the impact of perceived commerce risk on customer engagement.

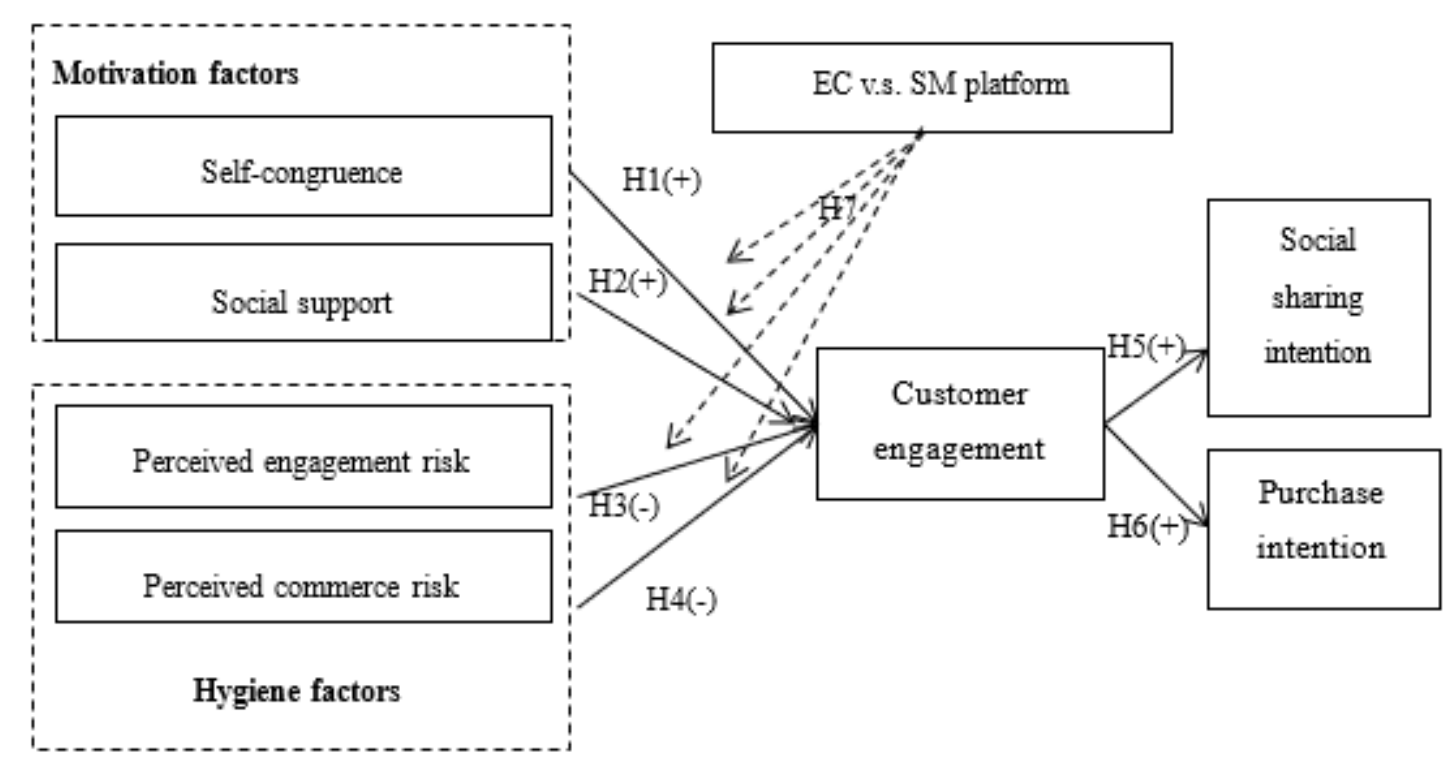

Figure 1. Research model

Based on the foregoing and existing literature, we developed a conceptual model of customer engagement in online social commerce platform. The research model of this paper is shown in figure 1. 


\section{Methodology}

\subsection{Data Collection and Analysis}

This paper used questionnaire survey to collect data. We obtained 824 valid questionnaires, accounting for $95.15 \%$ of the total number. We first conducted descriptive statistical analysis on the sample data to investigate the demographic characteristics of the sample. Results show that most are women, and the main age range is 18-25 years old; most are undergraduates, and most of them have 4-7 years of online shopping experience. Most of them buy goods online 1-5 times a month, which shows that most of them have rich online shopping experience.

We used AMOS 24.0 for our empirical analysis. Results show that KMO value is $0.956>0.5$, Bartlett test significance is $0.000<0.05$, which means the scale was suitable for factor analysis. Cronbach's $\alpha$ of all constructs is greater than 0.8 , which indicates the scale has high reliability. The factor loads of all constructs are greater than 0.6, thus they are all significant. The combination reliability of all constructs is greater than 0.8 , and the average variance extraction (AVE) is greater than 0.5, which indicates that the scale has good convergence validity. The square root of AVE of each construct is higher than the correlation between this construct and other constructs, that is, the discriminative validity of the scale is qualified.

\subsection{Results}

The fitting indexes of the model are as follows: $\chi^{2} / \mathrm{df}=3.640$, $\mathrm{SRMR}=0.0490, \mathrm{CFI}=0.914, \mathrm{TLI}=0.907, \mathrm{RMSEA}=0.057$, and all the indexes of the model meet the standards [30]. Then, the above assumptions are tested. The standardized path coefficient and significance of the model are shown in Figure 2, which confirms the influence of four constructs on customer engagement. The research shows that selfcongruence positively affects customer engagement $(\beta=$ $0.628, p<0.001$ ), and thus H1 was supported. Social support has a positive effect on customer engagement $(\beta=0.298, \mathrm{p}<$ $0.001)$, and $\mathrm{H} 2$ holds. Perceived engagement risk negatively affects customer engagement $(\beta=-0.092, p<0.05), \mathrm{H} 3$ holds. Perceived commerce risks have a negative effect on customer engagement $(\beta=0.130, p<0.001)$, and accept H4. From the significant results, perceived commerce risks have a stronger negative impact on customer engagement than perceived engagement risks. Customer engagement has a significant positive impact on social sharing intention $(\beta=0.842, p<$ $0.001)$ and purchase intention $(\beta=0.840, p<0.001)$, that is, both $\mathrm{H} 5$ and H6 hold true.

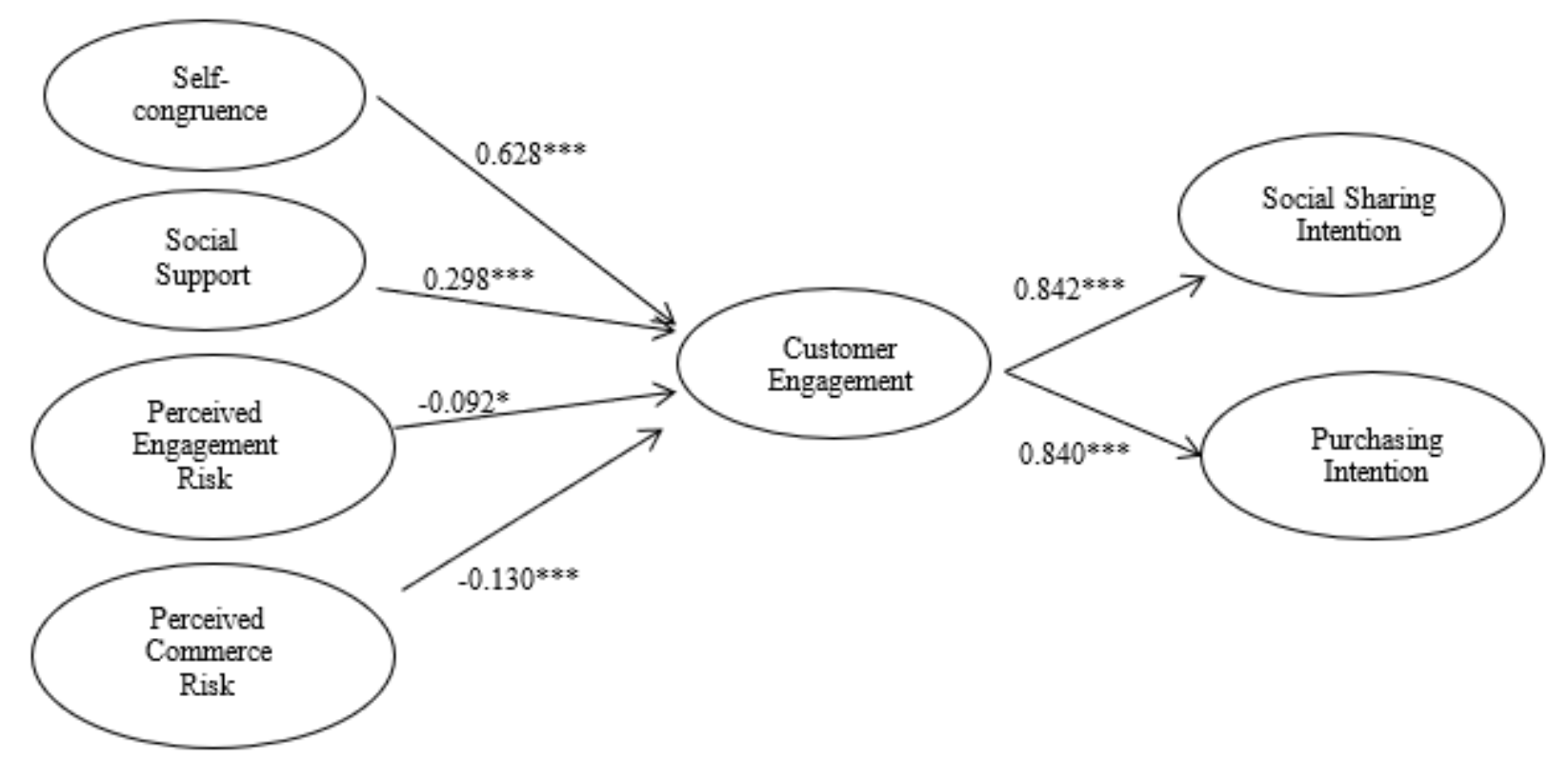

Figure 2. Analysis results of the model

In order to verify the moderating effect of social commerce website types on the model, we divided sample into two groups: e-commerce group and social media group, and the model is regressed within groups, the types of social commerce websites play a moderating role on the positive impact of self-congruence on customer engagement $(\mathrm{p}=0.009$ $<0.01$ ). From the perspective of path coefficient, compared with e-commerce websites, the self-congruence of social media websites has a more significant impact on customer engagement $\left(\beta_{\mathrm{ec}}=0.574<\beta_{\mathrm{sm}}=0.734\right)$, that is, $\mathrm{H} 7 \mathrm{a}$ is accepted. In the process of positive impact of social support on customer engagement, the types of social commerce websites also play a regulatory role $(p=0.009<0.01)$. Compared with social media websites, the social support of e-commerce websites has a more significant impact on customer engagement $\left(\beta_{\mathrm{ec}}=0.345>\beta_{\mathrm{sm}}=0.189\right)$, that is, $\mathrm{H} 7 \mathrm{~b}$ is accepted. There is no significant difference between ecommerce group and social media group in perceived engagement risk and perceived commerce risk on customer engagement $\left(\mathrm{p}_{\mathrm{PER}}=0.409>0.05, \mathrm{p}_{\mathrm{PCR}}=0.337>0.5\right)$, that is, $\mathrm{H} 7 \mathrm{c}$ and $\mathrm{H} 7 \mathrm{~d}$ are rejected.

\section{Discussion}

The research model combines social factors and risk factors to discuss the impact on customer engagement, which enriches the literature of social commerce to a certain extent. Results show that customers' perceived engagement risk and commerce risk have a significant negative impact on customer engagement, which also proves that social commerce customers are willing to avoid risks. The results also show that the platform type plays a moderating role in 
the positive impact of self-congruence on customer engagement, and the e-commerce platform has a more significant impact on it. When social support positively affects customer engagement, it is the social media platform that has a more significant impact on it. This series of studies provides theoretical support for the literature of social commerce platform comparison.

The results also have significant implications for social commerce enterprises. Enterprises should use certain marketing method to make the target people feel selfcongruence with the enterprises, to promote the customer engagement. Similarly, because social support has a positive impact on customer engagement, social commerce websites can provide creating multiple communication sections to enable customers get social support during their purchasing process, thus improving customer engagement.

The engagement risk perceived by customers will negatively affect customer engagement. Therefore, websites should try their best to take measures to reduce engagement risk perceived by customers, for example, in the information display situation that allows customers to freely choose their homepage, by reducing the exposure of private information to reduce the engagement risk. Moreover, because customers' engagement is also negatively affected by customer perceived business risks, social commerce websites should avoid the loss of property and theft of payment accounts that customers may face in the process of using websites, so as to reduce customer perceived business risks.

This paper has some limitations in the research process. First of all, most of the subjects are university students, which influences the generalization of this study. In future research, the sample data should be evenly distributed in all age sand career groups as far as possible, so as to make the research results more representative. Secondly, the consideration of customer behavior in this paper is limited, only social sharing and purchase intention are considered, and other customer behaviors are not considered. In future research, more complete consideration should be given to the construction of the model.

\section{References}

[1] FRIEDRICH T., SCHLAUDERER S.,OVERHAGE S. The impact of social commerce feature richness on website stickiness through cognitive and affective factors: An experimental study[J]. Electronic Commerce Research and Applications, 2019. 36.

[2] LIANG T.-P., et al. What Drives Social Commerce: The Role of Social Support and Relationship Quality[J]. International Journal of Electronic Commerce, 2014. 16(2): p. 69-90.

[3] YADAV M.S., et al. Social commerce: a contingency framework for assessing marketing potential[J]. Journal of Interactive Marketing, 2013. 27(4): p. 311-323.

[4] NG C.S.-P. Intention to purchase on social commerce websites across cultures: A cross-regional study[J]. Information \& Management, 2013. 50(8): p. 609-620.

[5] ARNOULD E., MUIZ A.,SCHAU H. How Brand Community Practices Create Value[J]. Journal of Marketing, 2009. 73: p. 30-51.

[6] SHEN X.-L., et al. Understanding the role of technology attractiveness in promoting social commerce engagement: Moderating effect of personal interest[J]. Information \& Management, 2019. 56(2): p. 294-305.
[7] LU B., FAN W.,ZHOU M. Social presence, trust, and social commerce purchase intention[J]. Computers in Human Behavior, 2016.

[8] CAMPBELL D.E., WELLS J.D.,VALACICH J.S. Breaking the ice in $\mathrm{B} 2 \mathrm{C}$ relationships: understanding pre-adoption ecommerce attraction[J]. Information Systems Research, 2013. 24: p. 219-238.

[9] MEHRABIAN A.,RUSSELL J.A., An Approach to Environmental Psychology. 1974, Cambridge, MA, US: The MIT Press.

[10] CHEUNG C., LEE M.,JIN X. Customer engagement in an online social platform: A conceptual model and scale development[J]. 2011.

[11] CENFETELLI R.T.,SCHWARZ A. Identifying and testing the inhibitors of technology usage intentions[J]. Information systems research, 2011. 22(4): p. 808-823.

[12] FARIVAR S., TUREL O.,YUAN Y. Skewing users' rational risk considerations in social commerce: An empirical examination of the role of social identification[J]. Information \& Management, 2018. 55(8): p. 1038-1048.

[13] LIANG T.-P.,LAI H.-J. Effect of store design on consumer purchases: an empirical study of on-line bookstores[J]. Information \& management, 2002. 39(6): p. 431-444.

[14] HOSANY S.,MARTIN D. Self-image congruence in consumer behavior[J]. Journal of Business Research, 2012. 65(5): p. 685691.

[15] AAKER J.L. The malleable self: The role of self-expression in persuasion[J]. Journal of Marketing Research, 1999. 36: p. 4557.

[16] CHEN J.,SHEN X.-L. Consumers' decisions in social commerce context: An empirical investigation[J]. Decision Support Systems, 2015. 79: p. 55-64.

[17] ISLAM J.U.,RAHMAN Z. The impact of online brand community characteristics on customer engagement: An application of Stimulus-Organism-Response paradigm[J]. Telematics and Informatics, 2017. 34: p. 96-109.

[18] ZHANG K.Z.K., BENYOUCEF M.,ZHAO S.J. Building brand loyalty in social commerce: The case of brand microblogs[J]. Electronic Commerce Research and Applications, 2016. 15: p. 14-25.

[19] PANSARI A.,KUMAR V. Customer engagement: the construct, antecedents, and consequences[J]. Journal of the Academy of Marketing Science, 2016. 45(3): p. 294-311.

[20] ALADWANI A.M. A quality-facilitated socialization model of social commerce decisions [J]. International Journal of Information Management, 2018. 40: p. 1-7.

[21] XU C., et al. It is not for fun: An examination of social network site usage[J]. Information \& Management, 2012. 49(5): p. 210217.

[22] SHUMAKER S.A.,BROWNELL A. Toward a theory of social support: Closing conceptual gaps[J]. Journal of social issues, 1984. 40(4): p. 11-36.

[23] FARIVAR S., TUREL O.,YUAN Y. A trust-risk perspective on social commerce use: an examination of the biasing role of habit[J]. Internet Research, 2017. 27(3): p. 586-607.

[24] ASHOER M.,SAID S. The impact of perceived risk on consumer purchase intention in Indonesia; a social commerce study. in Proceeding of the International Conference on Accounting. 2016. Management, Economics and Social Sciences.

[25] DOOLIN B., et al. Perceived risk, the Internet shopping experience and online purchasing behavior: A New Zealand 
perspective[J]. Journal of Global Information Management (JGIM), 2005. 13(2): p. 66-88.

[26] AKSOY L., et al. Managing brands and customer engagement in online brand communities[J]. Journal of service Management, 2013.

[27] BRODIE R.J., et al. Consumer engagement in a virtual brand community: An exploratory analysis[J]. Journal of business research, 2013. 66(1): p. 105-114.

[28] PCMAG.COM. Web Users Concerned About Privacy on Google, Facebook. Will 'Do Not Track' Help? 2011
2011.03.05];

Available

http://www.pcmag.com/article2/0, 2817, 2380089,00.asp.

[29] BANSAL G.,CHEN L. If they trust our e-commerce site, will they trust our social commerce site too? Differentiating the trust in e-commerce and s-commerce: The moderating role of privacy and security concerns. in MWAIS 2011 Proceedings. 2011.

[30] HOOPER D., COUGHLAN J.,MULLEN M.R., Structural Equation Modelling: Guidelines for Determining Model Fit, in Electronic Journal of Business Research Methods. 2008. p. 5360. 